\title{
Synthesis of Silver Nanoparticles from Different Citrus Fruit Peel Extracts and a Comparative Analysis on its Antibacterial Activity
}

\author{
M. Reenaa* and Aathira S. Menon \\ Department of Microbiology, Ethiraj College for Women, Chennai, Tamil Nadu, India \\ *Corresponding author
}

A B S T R A C T

Keywords

Silver

nanoparticles,

Citrus fruit peel

extracts,

Antibacterial

activity.

Article Info

Accepted:

26 June 2017

Available Online:

10 July 2017
Greener way of synthesizing nanoparticles has emerged as an alternative method, as it is eco- friendly and cost effective. The present work investigated the synthesis of silver nanoparticles with the aid of citrus fruit peel extracts (CFPE) under two different conditions such as sun dried and oven dried form. Characterisation of silver nanoparticles was carried out using UV-Visible spectroscopy. The colourless reaction mixture turned brown and displayed UV-Visible spectra characteristic of silver nanoparticles. The present study revealed that silver nanoparticles prepared from sun dried Citrus sinensis and mixed fruit peel extracts showed significant antibacterial activity against Pseudomonas aeruginosa, Escherichia coli and Salmonella typhimurium which are common food related pathogens.

\section{Introduction}

Nanoparticle synthesis in recent years has received considerable attention due to their unique properties and potential applications (Swathy et al., 2014).

The biological molecules undergo highly controlled assembly in order to make themselves suitable for nanoparticle synthesis. These nanoparticles are reliable and ecofriendly when compared with nanoparticles synthesized by other methods. The use of environmentally benign materials for the synthesis of nanoparticles offers numerous benefits in pharmaceutical and biomedical applications (Jain et al., 2009), as toxic chemical substances are not employed in their synthesis. The size and shape of the nanoparticles forms the basis for its usage as antimicrobial agents. Antibacterial activity of silver nanoparticles on antibiotic resistant, non-resistant and multidrug resistant strains disrupts bacterial enzyme activity, capable to penetrate bacterial cell membrane, creates structural imperfections thereby preventing bacterial proliferation (Caroling et al., 2013). Extensive work has been carried out on the biological synthesis of nanoparticles by using plant extracts (Subbaiya et al., 2014, Prathiba et al., 2015, Kirubha et al., 2015). Very few studies are available on the biosynthesis of silver nanoparticles from peel extracts (Aysha et al., 2014, Kokila et al., 2015) and seed 
extracts (Pandit, 2015). The present study illustrates the biofabrication of silver nanoarticles from fruit waste materials especially citrus fruit peel extracts. Characterisation of silver nanoparticles was done by using UV- Visible spectroscopy, which gives a preliminary confirmation of silver nanoparticles. An attempt has been made to compare the antibacterial activity of silver nanoparticles prepared from different citrus fruit peel extracts and mixed fruit peel extracts.

\section{Materials and Methods}

\section{Preparation of fruit peel extracts}

\section{Collection of citrus fruit peels and powder preparation}

Fruits such as Citrus sinensis, Citrus limon and Citrus limetta were obtained from the local market. Then the fruit peels were removed and cleaned thoroughly using distilled water to remove the dust particles adhering to the surface of the fruit peel. Then the fruit peels were kept for drying in two different conditions, one in microwave oven and the other under sunlight. In microwave oven it was dried at $160^{\circ} \mathrm{C}$ for 5 minutes and under sunlight it was dried for a period of 3-5 days. The dried peels were powdered and extract preparation for each type of fruit peels were done separately for both the techniques. Mixed fruit peel extract was also prepared in both the cases. Biosynthesis of silver nanoparticles (Caroling et al., 2013, Aysha et al., 2014, Kiruthika et al., 2016)

Five grams of powdered peel of each type of citrus fruit was added to $50 \mathrm{ml}$ of distilled water and boiled (water bath) for 15 minutes at $50^{\circ} \mathrm{C}$. Then the extract was filtered through Whatmann No. 1 filter paper and stored at $4^{\circ} \mathrm{C}$ for further use (as per standard procedures with slight modifications). Synthesis of silver nanoparticles involved addition of $2 \mathrm{ml}$ of $1 \mathrm{mM} \mathrm{AgNO}_{3}$ solution to $8 \mathrm{ml}$ of fruit peel extract and it was kept under dark condition for 24 hours at room temperature. One tube was kept as a control without addition of $1 \mathrm{mM} \mathrm{AgNO} 3$ solution. The same method was adopted for all other extracts.

\section{Characterisation of silver nanoparticles}

Silver nanoparticles are soluble in distilled water and the colour changes were observed visually. A dark brownish colouration indicates the formation of silver nanoparticles. The reduction of pure $\mathrm{Ag}+$ ions was monitored by measuring the UV spectrum of the reaction medium after overnight incubation after diluting a small aliquot of the sample in distilled water. The silver nanoparticles synthesized was analysed with the help of UV-Visible spectrophotometer $(300-600 \mathrm{~nm}$ range).

\section{Assessment of antibacterial activity of silver nanoparticles}

\section{Test pathogens}

Antibacterial activity of synthesized silver nanoparticles was tested against Salmonella typhimurium (MTCC 10312), Escherichia coli (MTCC 3224) and Pseudomonas aeruginosa (MTCC 6204). The bacterial strains employed in this work were procured from Microbial Type Culture Collections (MTCC) centre, Institute of Microbial Technology (IMTECH), Chandigarh.

\section{Silver nanoparticles as antibacterial agent}

The bacterial strains obtained from MTCC were used to determine the antibacterial activity of the silver nanoparticles. The experiment was carried out in Mueller Hinton agar by disc diffusion method. The inoculum was prepared and compared with Mac 
Farland's standard (0.5). Then the test culture was spread on to the agar surface. Discs with different concentrations $(10 \mu \mathrm{L}, 20 \mu \mathrm{L}, 30 \mu \mathrm{L})$ of silver nanoparticles (from peel extracts), silver nitrate and extract without silver nitrate were placed on the agar surface.

The same technique was followed for all the 8 extracts such as Citrus sinensis - sun dried and oven dried, Citrus limon -sun dried and oven dried, Citrus limetta - sun dried and oven dried and mixed peel extracts - sun dried and oven dried (Figs. 1 and 2). The plates were incubated at $37^{\circ} \mathrm{C}$ for 24 hours.

\section{Results and Discussion}

Synthesis of silver nanoparticles from citrus fruit peel extracts was visually confirmed by colour change after 24 hours of incubation at room temperature. The peak value between $400-500 \mathrm{~nm}$ ranges indicates the presence of silver nanoparticles by UV- Visible spectrophotometer analysis. Among all the citrus fruit peel extracts, the silver nanoparticles of Citrus sinensis (sun dried) (Fig. 1) extract showed good antibacterial activity against all the bacterial strains used. Mixed fruit peel extract (sun dried) also showed good antibacterial activity.

The antibacterial activity was confirmed on the basis of zone size exhibited by standard antibacterial agent (Ceftriaxone- $30 \mu \mathrm{g}$ was taken as common antibacterial agent).

UV - Visible spectroscopy is a simple and fast way to confirm the formation of silver nanoparticles. Synthesis of nano sized particles with antibacterial properties is of great interest in the development of new pharmaceutical products. Among the different types of extracts prepared, sun dried Citrus sinensis and mixed fruit peel extracts showed good antibacterial activity. Studies show that the positive charge on the Ag+ ions is crucial for its antimicrobial activity (Figs. 3-6).

Table.1 Zone of inhibition shown by silver nanoparticles synthesized from citrus

Fruit peel extracts against Pseudomonas aeruginosa

\begin{tabular}{|c|c|c|c|c|c|}
\hline \multirow[t]{2}{*}{ Microorganism } & \multicolumn{2}{|c|}{ Silver nanoparticles from } & \multicolumn{3}{|c|}{$\begin{array}{l}\text { Concentration and Zone size } \\
\text { (Diameter in } \mathbf{~ m m} \text { ) }\end{array}$} \\
\hline & & & $10 \mu \mathrm{l}$ & $20 \mu \mathrm{l}$ & 30 \\
\hline \multirow{8}{*}{$\begin{array}{l}\text { Pseudomonas } \\
\text { (MTCC 6204) }\end{array}$} & \multirow[t]{2}{*}{ Citrus sinensis } & SD & 10 & 18 & 21 \\
\hline & & OD & 8 & 14 & 20 \\
\hline & \multirow{3}{*}{$\begin{array}{l}\text { Citus limon } \\
\text { Citrus limetta }\end{array}$} & SD & 9 & 14 & 21 \\
\hline & & OD & 8 & 12 & 19 \\
\hline & & SD & 9 & 15 & 21 \\
\hline & \multirow{3}{*}{ Mixed peels } & OD & 7 & 13 & 20 \\
\hline & & SD & 12 & 16 & 23 \\
\hline & & OD & 10 & 15 & 21 \\
\hline
\end{tabular}

Table.2 Zone of inhibition shown by silver nanoparticles synthesized from citrus

Fruit peel extracts against Salmonella typhimurium

\begin{tabular}{|c|c|c|c|c|c|}
\hline \multirow[t]{2}{*}{ Microorganism } & \multicolumn{2}{|c|}{ Silver nanoparticles from } & \multicolumn{3}{|c|}{$\begin{array}{l}\text { Concentration and Zone size } \\
\text { (Diameter in } \mathbf{~ m m} \text { ) }\end{array}$} \\
\hline & & & $10 \mu \mathrm{l}$ & $20 \mu \mathrm{l}$ & 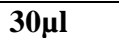 \\
\hline \multirow{8}{*}{$\begin{array}{l}\text { Salmonella typhimurium } \\
\text { (MTCC 10312) }\end{array}$} & Citrus sinensis & SD & 10 & 17 & 22 \\
\hline & \multirow[b]{2}{*}{ Citus limon } & OD & 9 & 15 & 20 \\
\hline & & SD & 9 & 13 & 20 \\
\hline & \multirow[b]{2}{*}{ Citrus limetta } & $\mathrm{OD}$ & 8 & 11 & 19 \\
\hline & & SD & 7 & 13 & 20 \\
\hline & \multirow{3}{*}{ Mixed peels } & OD & 7 & 11 & 19 \\
\hline & & SD & 12 & 17 & 22 \\
\hline & & OD & 10 & 13 & 21 \\
\hline
\end{tabular}


Table.3 Zone of inhibition shown by silver nanoparticles synthesized from citrus

Fruit peel extracts against Escherichia coli

\begin{tabular}{|c|c|c|c|c|c|}
\hline \multirow[t]{2}{*}{ Microorganism } & \multicolumn{2}{|c|}{ Silver nanoparticles from } & \multicolumn{3}{|c|}{$\begin{array}{c}\text { Concentration and Zone size } \\
\text { (Diameter in } \mathbf{~ m m} \text { ) }\end{array}$} \\
\hline & & & $10 \mu \mathrm{l}$ & $20 \mu \mathrm{l}$ & 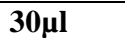 \\
\hline \multirow{8}{*}{$\begin{array}{l}\text { Escherichia coli (MTCC } \\
\text { 3224) }\end{array}$} & Citrus sinensis & SD & 10 & 15 & 21 \\
\hline & \multirow{3}{*}{ Citus limon } & OD & 8 & 14 & 20 \\
\hline & & SD & 9 & 15 & 21 \\
\hline & & OD & 8 & 13 & 19 \\
\hline & Citrus limetta & SD & 9 & 14 & 20 \\
\hline & \multirow{3}{*}{ Mixed peels } & OD & 7 & 14 & 20 \\
\hline & & SD & 11 & 15 & 22 \\
\hline & & OD & 10 & 15 & 20 \\
\hline
\end{tabular}

SD- Sun dried, OD- Oven dried

Fig.1 Sun dried citrus fruit peel powder

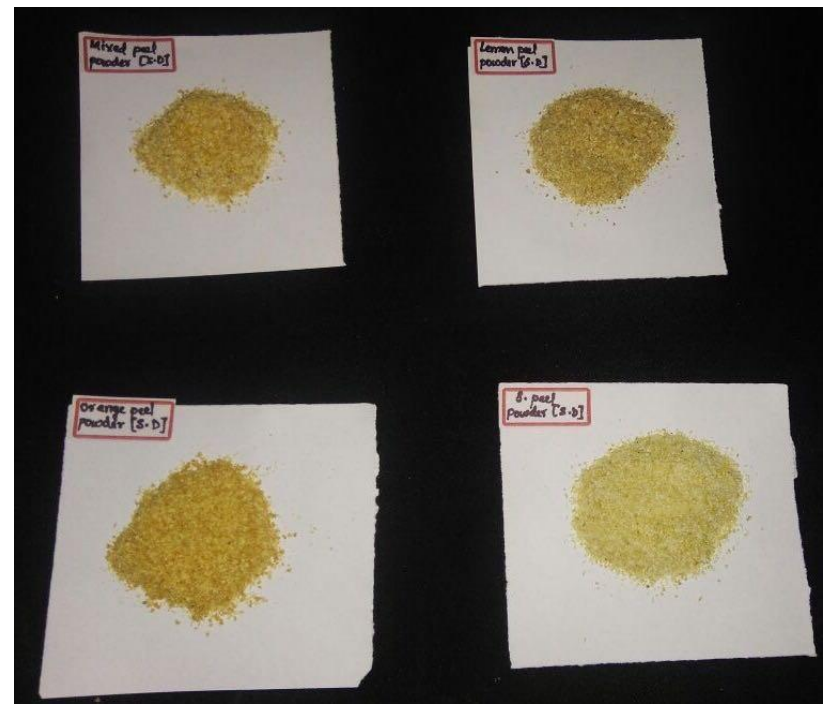

Fig.2 Oven dried citrus peel powder

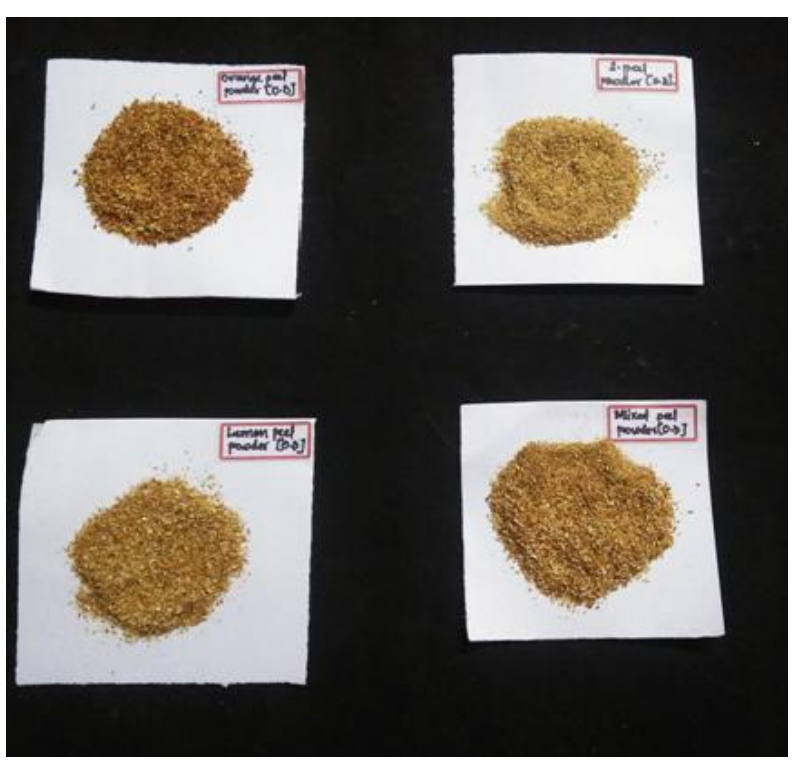


Int.J.Curr.Microbiol.App.Sci (2017) 6(7): 2358-2365

Fig.3 UV-Vis Characterisation of AgNPs of Citrus limetta
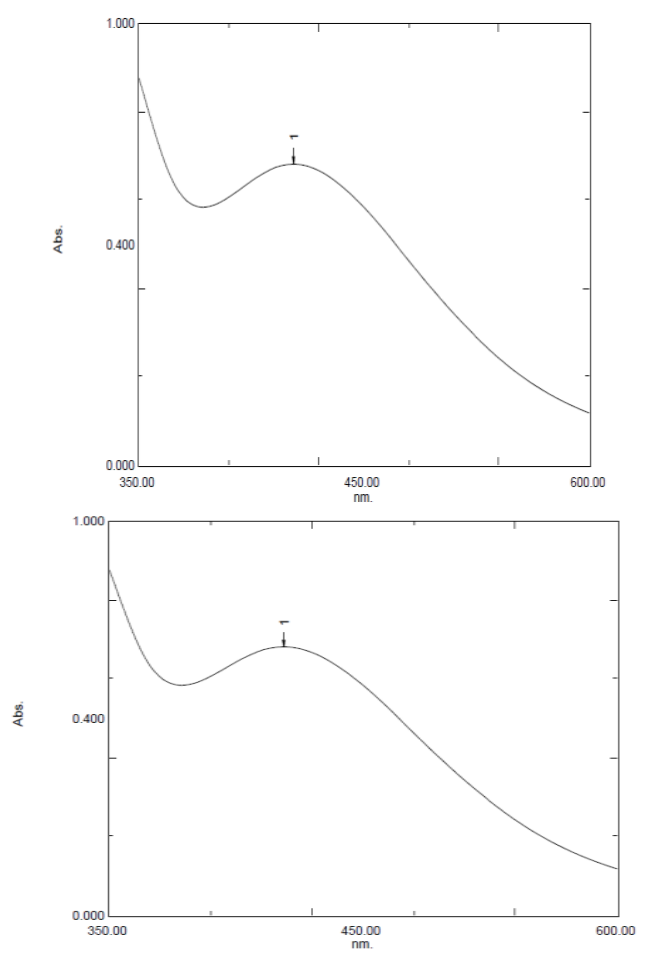

Fig.4 UV-Vis Characterisation of AgNPs of Citrus limon
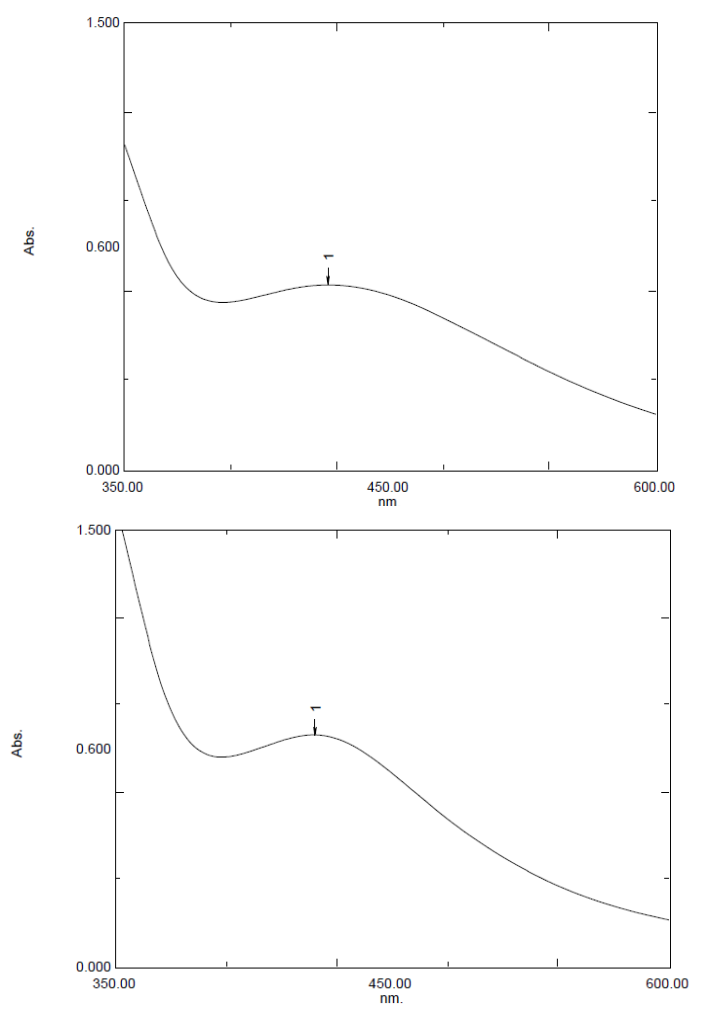
Fig.5 UV-Vis Characterisation of AgNPs of Citrus sinesis
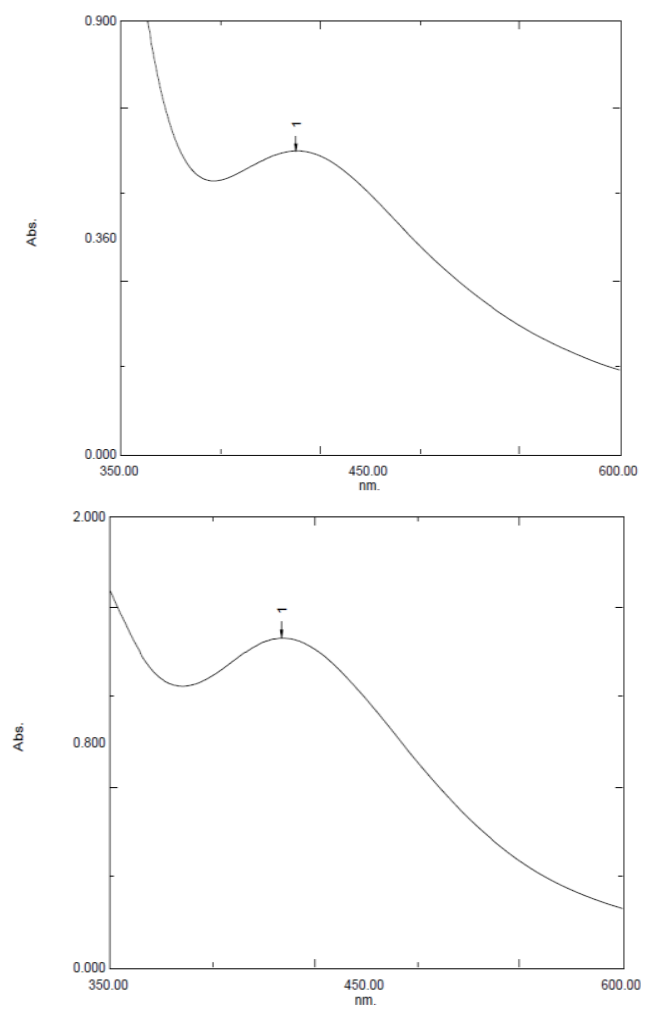

Fig.6 UV-Vis Characterisation of AgNPs of Mixed Extract
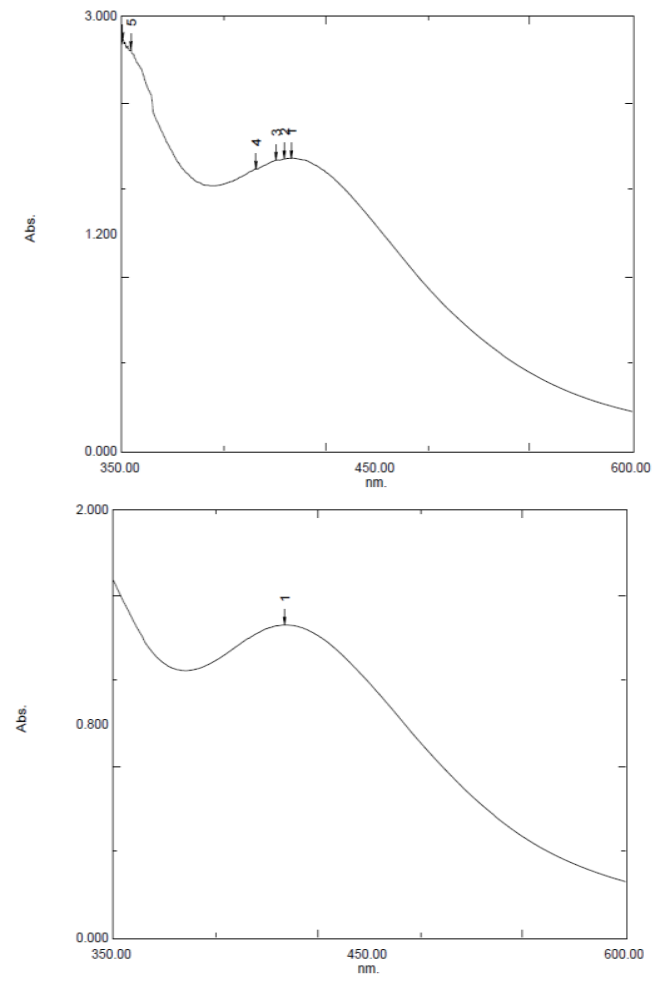
Fig.7 AgNPs of mixed peel extract (SD) showing antibacterial effect on Pseudomonas aeruginosa

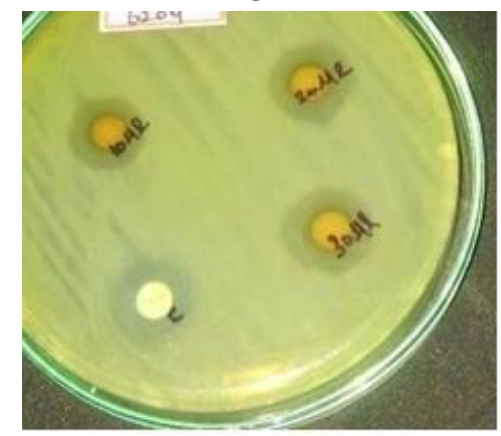

Fig.8 AgNPs of mixed peel extract (SD) showing antibacterial effect on Salmonella typhimurium

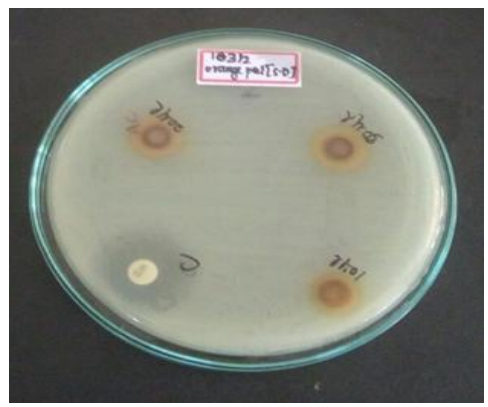

They not only interact with the surface of the microbial membrane but can also penetrate into the cell (Banker et al., 2010).

Thus the present study is a preliminary work on the biosynthesis of silver nanoparticles from citrus fruit peel extracts and further it was found that, silver nanoparticles obtained from sun dried Citrus sinensis and mixed fruit peel extracts showed good antibacterial activity (Figs. 7 and 8; Tables 1-3).

In future, these methods can be employed in drug delivery system as it is cost effective when compared with the usage of conventional antibiotics and also in food packaging to prevent spoilage of food materials but only after performing an intrinsic study on the preparatory methods.

\section{Acknowledgement}

The authors are thankful to the Management, Ethiraj College for Women for providing laboratory facilities to carry out this work. One of the authors Dr. M. Reenaa wish to thank her Mentor Dr. R. Gowrisankar, Lab Lead -
Immunobiology Laboratory, CDC, Atlanta, USA for his insistent guidance and support.

\section{References}

Aysha, OS, and Nisha, NS. 2014. Biosynthesis of silver nanoparticles using Citrus limon (LINN) Burm. F. peel extract and its antibacterial property against selected urinary tract pathogens. Journal of Biological \& Scienific Opinion. 2(3):248252.

Bankar, A., Joshi, B., Ravikumar, A., and Zinjarde, S. 2010. Banana peel extract mediated novel route for the synthesis of silver nanoparticles. Colloids and Surfaces A: Physicochemical and Engineering Aspects. 368:58-63.

Caroling, G., Tiwari, SK., Mercy Ranjitham A., and Suja, R. 2013. Biosynthesis of silver nanoparticles using aqueous broccoli extract- characterization and study of antimicrobial, cytotoxic effects. Asian Journal of Pharmaceutical and Clinical Research. 6(4):165-172.

Chandran, PS., Chaudhary, M., Parricha, R., Ahmad, A., and Sastry, M. 2006. 
Synthesis of gold nano triangles and silver nanoparticles using aloe vera plant extract. Biotechnology Progress. 22:577583.

Elumalai, EK, Prasad TNVKV, Hemachandran, J., Theresa, VS., Thirumalai, T., and David, E.2010. Extracellular synthesis of silver nanoparticles using leaves of Euphorbia hirta and their antibacterial activities. Journal of Pharmaceutical Sciences and Research. 2(9):549-554.

Hari Priyaa, G., and Satyan, KB. 2014. Biological synthesis of silver nanoparticles using Ginger (Zingiber officinale) extract. Journal of Environmental Nanotechnology. 3(4):3240.

Jain,D., Daima, KH., Kachhwaha,S., and Kothari, SL.2009. Synthesis of plant mediated silver nanoparticles using papaya fruit extract and evaluation of their antimicrobial activities. Digest Journal of Nanomaterials and Biostructures. 4(3):557-563.

Kirubha, R., and Alagumuthu, G. 2015. Investigation of antibacterial properties of silver nanoparticles using Aerva lanata extract. Indo American Journal of Pharmaceutical Sciences. 2(3):668-675.

Kiruthika, N., and Somanathan, T. 2016. Biofabrication of silver nanoparticles from fruit waste extract and their application towards antimicrobial activity. International Journal of Pharma and Biosciences. 7(1):7-11.

Kokila, T., Ramesh, P., and Geetha, D. 2015. A biogenic approach for green synthesis of silver nanoparticles using peel extract of Citrus sinensis and its application. International Journal of Chem Tech Research. 7(2):804-813.

Nisha, MH, Tamileswari, R., Jesurani, S.,
Kanagesan, S., Hashim, M., and Alexander, PCS. 2015. Green synthesis of silver nanoprticles from pomegranate (Punica granatum) leaves and analysis of antibacterial activity. International Journal of Advanced Technologyin Engineering and Science. 3(6):1-8.

Pandit,R. 2015. Green synthesis of silver nanoparticles from seed extract of Brassica nigra and its antibacterial activity. Nusantara Bioscience. 7(1):1519.

Prathibha, S., Packiyam, JE, Bhat, PR., Jayadev, K., and Shetty, S. 2015. Green synthesis of silver nanoparticles from fruit extracts of Terminalia chebula Retz. And their antibacterial activity. International Journal of Research in Biosciences. 4(2):29-35.

Shet, AR., Ghose, P., Patil, L., and Hombalimath, V. 2015. A preliminary study on green synthesis and antibacterial activity of silver nanoparticles. International Journal of Current Biotechnology. 3(2)1-6.

Singha, S., Neog, K., Kalita, PP., Talukdar, N., and Sarma, MP. 2014. Biological synthesis of silver nanoparticles by Neptunia oleraceae. International Journal of Basic and Applied Biology. 2(2):5559.

Subbaiya, R., Shiyamala, M., Revathi, K., Pushpalatha, R., and Masilamani, SM. 2014. Biological synthesis of silver nanoparticles from Nerium oleander and its antibacterial and antioxidant property. International Journal of Current Microbiology and Applied Sciences. 3(1):83-87.

Swathy, B. 2014. A review of metallic silver nanoparticles. IOSR Journal of Pharmacy. 4(7):38-44.

\section{How to cite this article:}

Reenaa, M. and Aathira S. Menon. 2017. Synthesis of Silver Nanoparticles from Different Citrus Fruit Peel Extracts and a Comparative Analysis on its Antibacterial Activity. Int.J.Curr.Microbiol.App.Sci. 6(7): 2358-2365. doi: https://doi.org/10.20546/ijcmas.2017.607.337 